\title{
Effects of organic composition on mesophilic anaerobic digestion of food
}

waste

Yangyang Li ${ }^{\mathrm{a}, \mathrm{b}}$, Yiying Jin ${ }^{\mathrm{a}, \mathrm{b},{ }^{*},}$, Aiduan Borrion ${ }^{\mathrm{c}}$, Hailong $\mathrm{Li}^{\mathrm{d}}$, Jinhui $\mathrm{Li}^{\mathrm{a}, \mathrm{b}}$

a, School of Environment, Tsinghua University, Beijing 100084, China

b, Key Laboratory for Solid Waste Management and Environment Safety (Tsinghua University), Ministry of Education of China, Tsinghua University, Beijing 100084, China

c, Dept of Civil, Environ \&Geomatic Eng, University College London, London WC1E 6BT, UK

d, Mälardalen University, School of Business, Society and Engineering, SE-721 23 Västerås, Sweden

\section{Abstract}

Anaerobic digestion of food waste (FW) has been widely investigated, however, little is known about the influence of organic composition on the FW digestion process. This study aims to identify the optimum composition ratios of carbohydrate (CA), protein (CP) and lipid (EE) for maintaining high methane yield and process stability. The results show that the $\mathrm{CA}-\mathrm{CP}-\mathrm{EE}$ ratio was significantly correlated with performance and degradability parameters. Controlling the $\mathrm{CA}-\mathrm{CP}-\mathrm{EE}$ ratio higher than 1.89 (CA higher than $8.3 \%, \mathrm{CP}$ lower than 5.0\%, and EE lower than 5.6\%) could be an effective way to maintain stable digestion and achieve higher methane production (385-627 $\mathrm{mL} / \mathrm{gVS}$ ) and shorter digestion retention (196-409 h). The CA-CP-EE ratio could be used as an important indicator for digestion performance. To effectively evaluate organic reduction, the concentration and removal efficiency of organic compositions in both solid phases and total FW should be considered.

Keywords: Food waste; Anaerobic digestion; Organic composition; Methane

\footnotetext{
* Corresponding author. Address: School of Environment, Tsinghua University, Beijing, China. Tel.: +8610 62794352; Fax: +861062797618. E-mail address: jinyy@tsinghua.edu.cn (Y. Jin).
} 


\section{Introduction}

Anaerobic digestion (AD) has been widely used for treating food waste (FW), and the digestion performance (e.g. biogas production, organic reduction, inhibition characteristics and process stability) is highly dependent on the feedstock's characteristics (Wagner et al., 2013). FW consists of three principal organic components: carbohydrates, proteins and lipids, and the volatile solid to total solid (VS/TS) ratios typically range from 80 to $97 \%$ (Jin et al., 2015; Zhang et al., 2014; Zhang et al., 2007). Therefore, significant variations in digestion performance could occur during biological conversion processes.

U Kun Kiran et al. (2014) conducted a literature review on the methane production capacities of FW, and reported a production range of 220-546 mL/g VS, with VS reduction between 70-95\%. A study by Cho et al. (1995) on different types of feedstock (i.e. cooked meat, boiled rice, fresh cabbage and mixed FW) reported methane production between $294-482 \mathrm{~mL} / \mathrm{g}$ VS. Studies have shown that carbohydrate-rich feedstock yields more hydrogen than protein- and lipid-rich substrates (De Gioannis et al., 2013), while lipid-rich feedstock has higher biochemical methane potential (BMP) than carbohydrate-rich and protein-rich feedstocks (Angelidaki and Sanders, 2004). In contrast, studies have also shown that protein-rich substrates yield higher levels of ammonia, which inhibits methanogens, while carbohydrate-rich substrates result in undesirable $\mathrm{C} / \mathrm{N}$ ratios due to nutrient limitations and rapid acidification (Paritosh et al., 2017). Lipid-rich feedstock strongly inhibits 
methanogenic activity (Alves et al., 2009; Cirne et al., 2007; Sun et al., 2014; Yuan and Zhu, 2016; Zhang et al., 2014), which is due to the formation of long chain fatty acids (LCFAs) during lipid degradation, such as the 18-C LCFA (Wan et al., 2011). Strong inhibition was reported by Cirne et al. (2007) when lipid content amounted to $31 \%$ (w/w, COD basis). In addition to the individual effects of three compositions on the digestion process, interactions between carbohydrates and proteins during the digestion process have also been reported by Breure et al.(1986).

A considerable amount of research has been devoted to the influence of organic composition on the digestion performance of FW (including mono- and co-digestion), however, studies were confined to using synthetic FW (Alibardi and Cossu, 2016), collected FW with limited composition ranges (Li et al., 2016; Rajagopal et al., 2013; Wang et al., 2014; Yin et al., 2014; Zhang et al., 2005) and co-digestion with other organic waste (e.g., sewage (Koch et al., 2015), cattle manure (Zhang et al., 2013), piggery wastewater (Zhang et al., 2011) and yard waste (Brown and Li, 2013)), or simplified to focus on optimising $\mathrm{C} / \mathrm{N}$ ratios (with optimum reported values within 20-60) (Astals et al., 2014; Mata-Alvarez et al., 2014). The organic compositions of FW often vary with factors such as food availability, seasonal variation and consumption patterns (Kobayashi et al., 2012). For a given FW C/N ratio, the carbohydrate, protein and lipid content can differ. Due to differences in substrate characteristics, inoculums and digestion parameters (e.g., temperature, retention time and digester type) (Rajagopal et al., 2013; Xie et al., 2016; Yuan and Zhu, 2016), there 
is little information that evaluates the influence of organic composition on the FW mono-digestion process, or suggests appropriate composition blending ratios. It would be interesting to compare the effects of the $\mathrm{C} / \mathrm{N}$ ratio and the organic composition blending ratio, and then suggest a more appropriate indicator for digestion performance.

This study aimed to evaluate the effects of organic composition on the digestion process stability, methane production performance and organic degradation properties at different retention times (RT) under a mesophilic temperature. Kinetic studies were then carried out to describe the methane production process. Additionally, statistical analyses (e.g., ANOVA, Pearson correlation analysis, Principal component analysis and Cluster analysis) were used to determine the correlations between the parameters (e.g., digestion performance, process kinetics and biodegradability) and the three components, discuss possible mechanisms, and provide comprehensive and comparative conclusions on FW AD. Finally, conclusions were drawn for which factors could potentially increase methane yields during FW digestion and determine the optimum proportion of the three organic components. The results obtained in this study could enhance understanding of how the variability of organic components affects methane yields from FW. Detailed information on performance and degradability characterisation could help to predict and optimise operating parameters by adjusting the compositions of organic components, as well as identify potential economic benefits of the FW digestion process. 


\section{Materials and Methods}

\subsection{FW and inoculum}

The FW was collected from different canteens. Impurities in the collected FW (e.g., big bones, plastics and metals) were manually removed before the FW was macerated into 1-2 mm particles by a macerator. The samples were stored at $4{ }^{\circ} \mathrm{C}$ prior to use. The ranges of variation of FW compositions were obtained from a literature review and measurements of samples from 5 typical Chinese cities (e.g. Beijing in North China; Jiaxing in Zhejiang province, East China; Xining in Qinghai province, Northwest China; Qingdao in Shandong province, coastal East China and Guiyang in Guizhou province, South China).

Seed sludge was obtained as an inoculum from a steady-operation digester $\left(37^{\circ} \mathrm{C}\right)$ in a FW treatment plant in Beijing, China. After a two-day gravity sedimentation period, the supernatant was discarded and the rest was passed through a 2-mm sieve to remove large particles/grit. Characteristics of FW and inoculum were shown in Table 1.

Table 1 (a). Table 1 (b).

\subsection{Batch digestion experiment}

The BMP assay has been proven to be a relatively simple and reliable method for determining the extent and rate of converting organic matter to methane. Batch tests were conducted at $37{ }^{\circ} \mathrm{C}$ using an Automatic Methane Potential Test System II (AMPTS II), supplied by Bioprocess Control (Lund, Sweden). All the reactors were started at the same time, and agitation was synchronous, with the same speed and 
intervals between all reactors. Thus, evaluating the biodegradability and decomposition rate of organic materials was more accurate than other batch assays.

The AMPTS II system contained $500 \mathrm{~mL}$ (total volume) glass bottles (A), and was used to measure the real-time methane productivity and kinetics, while the system with $2 \mathrm{~L}$ (total volume) glass bottles $(B)$ was used for collecting samples and detecting indicators. All the bottles in both systems were fed with the same samples that had the same inoculation ratios $(\mathrm{FW} /$ inoculum $=0.5, \mathrm{VS}$ basis $)$. To achieve accurate results, it is important to collect samples at the correct times (e.g. inhibition stage, recovery stage and the final stage). Digestion system $A$ was started two days before system $B$ to understand how sample collection time affected the methane yield patterns.

\subsection{Kinetic study}

A transference function was used to determine the methane production potential, the maximum methane production rate and lag time for $\mathrm{AD}$, which has been used in previous studies (Donoso-Bravo et al., 2010; Li et al., 2012; Pagliaccia et al., 2016). This model, used mainly for control purposes, considers that any process could be analysed as a system receiving inputs and generating outputs, and was evaluated (Eq. (1)) (Donoso-Bravo et al., 2010). The apparent hydrolysis rate coefficient $(k)$ was obtained using the first-order equation, which was assumed for the hydrolysis of particulate organic matter (Eq. (2)) (Veeken and Hamelers, 1999).

$$
\begin{aligned}
& B=B_{0} \times\left\{1-\exp \left[-\mu_{\mathrm{m}} \times(t-\lambda) / B_{0}\right]\right\} \\
& B=B_{0} \times[1-\exp (-k \mathrm{t})]
\end{aligned}
$$


where $B$ is the cumulative methane production at digestion time $t, B_{0}$ is the methane production potential $(\mathrm{mL} / \mathrm{g} \mathrm{VS}), \mu_{\mathrm{m}}$ is the maximum methane production rate $(\mathrm{mL} / \mathrm{g}$ $\mathrm{VS} \mathrm{h}), \lambda$ is the lag time (h), $k$ is the first-order hydrolysis rate constant $\left(\mathrm{d}^{-1}\right)$ and $t$ is time (h).

\subsection{Analytical methods}

TS and VS were determined according to the standard methods of the American Public Health Association (APHA, 1915). pH was measured using a pH meter (FE20, Mettler, Switzerland). The concentrations of protein and lipid (expressed as EE) were determined following the Kjeldahl method and by using a Soxhlet device, respectively (Jones Jr, 1991; Langrish). Concentrations of total ammonia nitrogen (TAN) and free ammonia nitrogen (FAN) were determined as previously reported (Siles et al., 2010). VFA and ethanol were measured by Agilent Gas Chromatograph (Agilent GC-7890A, California, USA) equipped with a flame ionization detector.

\subsection{Statistical analysis}

Statistically significant differences in the results (changes in organic reduction and process parameters) were identified by ANOVA analysis $(p<0.05)$ using $\mathrm{R}$ software 3.3.2. Pearson correlation $(p<0.05)$ was also determined to discuss significant relationships between the above parameters, using IBM SPSS Statistics 20. Principal component analysis (PCA) was conducted on the data, and leave-one-out cross validation was used, and conducted by IBM SPSS Statistics 20 . The data in this study were subjected to cluster analysis, which can help to simplify and organise datasets and 
generate useful generalisations that can garner meaningful insight. Cluster analysis was carried out to classify different cases based on the principle of the nearest neighbour. Between-group linkage was chosen as the cluster method and measured using squared Euclidean distance by IBM SPSS Statistics 20.

\section{Results and Discussion}

\subsection{Performance of operation parameters}

\subsection{1. $p H$}

The $\mathrm{pH}$ declined to its lowest values $\left(\mathrm{pH}_{\mathrm{min}}\right)$ on day 1 , varying from 7.45 to 7.74 . After 30 days, the final $\mathrm{pH}$ was between 7.79-7.99 (Fig. 1a). The pH values for all of the digesters were within an ideal range for $\mathrm{AD}$, i.e. $4.0-8.5$ for fermentative bacteria and 6.5-7.2 for methanogens (Zhang et al., 2014), and the alkaline microenvironment showed no VFA accumulation during digestion.

The maximum $\mathrm{pH}\left(\mathrm{pH}_{\max }\right)$ was significantly influenced by the compositions of $\mathrm{FW}$. Higher protein and lipid content resulted in higher $\mathrm{pH}_{\max }$ values, but higher carbohydrate contents resulted in lower $\mathrm{pH}_{\max }$ values. This could be explained by carbohydrate having a higher hydrolysis rate than lipids and proteins during the AD process, leading to a more rapid VFA production, while protein provides necessary buffering capacity. Fig. 1.

Additionally, $\mathrm{pH}$ is largely influenced by a number of chemical balances within a medium. Owing to a delay in reaction time, $\mathrm{pH}$ should be recorded with other parameters (e.g., VFA concentration, ammonia concentration and biogas composition). 


\subsubsection{VFA}

(1) VFA concentration

VFA concentration increased rapidly to its peak values (VFA $A_{\max }$ ) within the first $24 \mathrm{~h}$ (104-1624 mg/L), and remained steady from the 20th day onwards (0-34 mg/L), indicating longer retention times for complete degradation with increasing $\mathrm{CA}-\mathrm{CP}-\mathrm{EE}$ ratios (Fig. 1b). Two VFA generation peaks were identified for FW with CA-CP-EE ratios higher than 1.89. The first peak indicated intense VFA production within a short duration, and higher peak values than the second peak. This was likely to be due to the high carbohydrate concentration $(9.3-11.0 \%$, wet basis), which was biodegraded more rapidly than proteins and lipids, and then contributed to the first peak. The second peak, varying from 114 to $238 \mathrm{mg} / \mathrm{L}$ between days $4-11$, could be due to the subsequent degradation of proteins and lipids. The second peak could also result from the further stepwise degradation of some soluble organics, such as carbohydrates, because a rapid decrease in carbohydrate concentration during the initial 1-3 days is often followed by slower degradation (Yang et al., 2015). When the CA-CP-EE ratios were lower than 1.89 , however, a single peak was observed. As the degradation of carbohydrates was more rapid than that of proteins and lipids, a possible reason for the single peak from samples with lower CA-CP-EE ratios could be LCFA accumulation with the hydrolysis of lipids, thus inhibition of LCFA occurred. This could delay the degradation of carbohydrate and integrated it with the other organics.

The degradation of organic compounds in FW led to VFA production, resulting in a 
decrease of $\mathrm{pH}$, and in this study, higher VFA content corresponded with lower $\mathrm{pH}$. A positive significant relationship was found between the values of the first peaks $\left(\mathrm{VFA}_{\max }\right)$ and $\mathrm{pH}_{\max }$. In contrast, higher protein and lipid content contributed to higher $\mathrm{VFA}_{\max }$ values, but the opposite was achieved for higher carbohydrate content and $\mathrm{CA}-\mathrm{CP}-\mathrm{EE}$ ratios $(p<0.01)$. These findings suggest that alkaline $\mathrm{pH}$ values benefitted anaerobic carbohydrate, protein and lipid hydrolysis, leading to high VFA concentrations. These findings are consistent with those from previous studies (Dahiya et al., 2015; Noike et al., 1985) that found that, in an alkaline microenvironment, carbohydrate and protein hydrolysis was enhanced by the ionization of charged groups (e.g. carboxylic groups), while lipids were less soluble under acidic conditions $(5.5-6.0)$.

(2) VFA compositions

Acetic and propionic acid were intensely produced during the first day of AD (Fig. 1c and Fig. 1d). Propionic acid was the main components of VFA on day 1, which accounted for $20-90 \%$, and was followed by a sharp decrease. From the third day, propionic acid concentration was low (less than $0.05 \mathrm{mg} / \mathrm{L}$ ) in all of the digesters (Fig. 1d), which could have been due to low loading rates of organics (Lin et al., 2011) and high seed sludge activity. Additionally, the concentrations of butyric and isobutyric acid were less than $60 \mathrm{mg} / \mathrm{L}$ on day two, and then dropped below the detection limit $(0.05 \mathrm{mg} / \mathrm{L})$ during the following 28 days. Similar findings were reported by Noike et al. (1985). Butyric and valeric acid were generated in the first $12 \mathrm{~h}$, but could not be 
detected after $48 \mathrm{~h}$, indicating that it was completely consumed during the digestion process. It can be concluded that acetic acid was the primary acid released during acidification (Fig. 1c).

The concentrations of proteins and lipids were positively correlated with the maximum propionic acid concentration, while maximum propionic acid concentration was negatively correlated with carbohydrate concentration. Lipid content was the main factor that influenced the maximum n-valeric acid concentration $(p<0.05)$, while iso-valeric acid concentration was positively correlated with protein content $(p<0.01)$ and negatively correlated with carbohydrate content $(p<0.01)$. Additionally, the final VFA distribution indicated that the final propionic acid concentration ranged from 6 to $61 \mathrm{mg} / \mathrm{L}$ when the CA-CP-EE ratios were lower than 1.89 (carbohydrate: $3.1-8.3 \%$, protein: $5.0-7.9 \%$, and lipid: 5.6-10.2\%), while it was completely degraded in the other assays. The accumulation of propionic acid, which is difficult to degrade, suggested that the methanogenesis step failed. These results indicate that controlling $\mathrm{CA}-\mathrm{CP}-\mathrm{EE}$ ratios to levels higher than 1.89 (with carbohydrate concentrations higher than $8.3 \%$, proteins lower than $5.0 \%$ and lipids lower than 5.6\%) could be an effective way for maintaining a stable digestion process with higher methane production and shorter digestion retention (Table 2).

\subsubsection{Ethanol}

Ethanol concentration (ranging from 129 to $485 \mathrm{mg} / \mathrm{L}$ ) increased to several peaks as the RT increased, and varied very little after 15-17 days (Fig. 2a). The concentration 
was lower than those of VFA and acetic acid, which is consistent with results from other researchers (Tang et al., 2008). Lipid content was positively correlated $(p<0.05)$ with the final ethanol concentration, while carbohydrate and protein content had no significant effect $(p>0.05)$.

An alkaline environment can promote the hydrolysis process (Dahiya et al., 2015) and contribute to ethanol production, thus a positive correlation between ethanol concentration and $\mathrm{pH}_{\max }(p<0.01)$ was found. As ethanol can inhibit hydrolytic enzymes (Wyman, 1996), lower VFA concentrations corresponded with higher ethanol content. The occurrence time of the ethanol concentration peak was 1 to 6 days later than that of VFA (Fig. 1b). Additionally, higher acetic acid concentration inhibits propionic acid degradation (Mawson et al., 1991), and ethanol content was positively correlated with propionic acid concentration $(p<0.05)$. Fig. 2 .

\subsubsection{TAN and FAN}

The concentration of TAN (1654-2441 mg/L) and FAN (58-125 mg/L) initially decreased on day one, but recovered and continuously increased on days 3-5 (Fig. 2b and 2c). These were little to no increases in TAN and FAN concentrations after day seven, indicating that protein biodegradation had completed, or a balance was achieved between protein production and consumption.

$\mathrm{NH}_{4}{ }^{+} / \mathrm{NH}_{3}$ were released into the liquid phase during protein degradation, and their concentrations depended on the protein content of the feedstock, therefore, TAN and FAN content were positively correlated with protein content $(p<0.01) . \mathrm{pH}$ and 
alkalinity also increased during the degradation of amino acids due to the consumption of protons, and both TAN and FAN were positively correlated with lipid content and negatively correlated with carbohydrate content.

$\mathrm{pH}_{\max }$ and VFA $\mathrm{max}_{\max }$ were significantly, positively correlated with TAN and FAN $(p<$ 0.01). High ammonia levels can cause inhibition, characterised by low methane yield and high VFA concentration in effluents. As shown in Fig. 2b, it took less time for FW with higher protein content to reach inhibition concentrations of TAN (over $1500 \mathrm{mg} / \mathrm{L}$ (Rajagopal et al., 2013)). In contrast, FAN was not inhibited through the entire digestion process (Fig. 2c). Though all the assays in this study yielded a TAN concentration higher than $1500 \mathrm{mg} / \mathrm{L}$, the final VFA concentrations were low, indicating high biomethane conversion efficiency, while the final $\mathrm{pH}$ was within an appropriate range. These findings suggest that the conditions causing instability in one reactor do not necessarily cause problems in another, and, therefore, defining TAN levels as an indicator of the state of an anaerobic process would not be possible, because feedstocks have specific TAN that can be considered stable for the reactor.

\subsection{Methane yields and kinetic analysis}

\subsubsection{Methane production}

The methane yield ranged from 385 to $627 \mathrm{~mL} / \mathrm{gVS}$ after 30 days of digestion (Fig. 2d). The highest yield was achieved from FW with a CA-CP-EE ratio of 1.60, which consist of $6.9 \%$ lipid, $7.9 \%$ protein and $3.1 \%$ carbohydrate. Lipid was the main factor that influenced methane yield, exhibiting a significant positive correlation $(p<0.01)$ 
due to its higher BMP than carbohydrates and proteins. The specific methane yield varied between 12.69 and $43.16 \mathrm{~mL} /(\mathrm{gVS} \mathrm{h})$, and the maximum value $\left(R_{\max }\right)$ was obtained from $\mathrm{FW}$ with a $\mathrm{CA}-\mathrm{CP}-\mathrm{EE}$ ratio of 1.89 (5.5\% lipid, $4.6 \%$ protein and $9.2 \%$ carbohydrate).

To evaluate the extent of biomethane conversion from organics, the ratios of the measured values to theoretical methane yields $(\mathrm{M} / \mathrm{T})$ were calculated, and the latter was calculated according to a method reported by Angelidaki and Sanders (2004). M/T ratios ranged from $86 \%$ to $96 \%$ (Fig. 2 d), and showed strong positive correlations with $\mathrm{C} / \mathrm{N}$ ratios $(p<0.01)$. Over $90 \%$ of the theoretical methane yields were achieved when the $\mathrm{C} / \mathrm{N}$ ratio fell between $17-18$. As the $\mathrm{M} / \mathrm{T}$ ratios decreased with increasing propionic acid concentrations $(p<0.01), \mathrm{pH}_{\max }(p<0.05), \mathrm{VFA}_{\max }(p<0.01)$, FAN $(p$ $<0.01)$ and TAN $(p<0.01)$, an appropriate degree of hydrolysis and sufficient buffering capacity could contribute to high methane conversion efficiency. Although the $\mathrm{M} / \mathrm{T}$ ratios were negatively correlated with protein $(p<0.01)$, this does not suggest that continuously decreasing protein content could increase methane yield, because buffering from ammonia and ammonium during the breakdown of proteins would be required. The methane yield, however, had no significant relationship with $\mathrm{pH}_{\max }$ and TAN, but it had a significant positive relationship with VFA $\max$ and FAN. This suggests that enhancing the solubilisation and hydrolysis of organics could be an effective way of maintaining high methane production. The above findings indicate that methane yield and kinetics were greatly influenced by FW compositions. 


\subsubsection{Kinetic study of methane production}

The results of the parameters estimated from two models are presented in Table 2, with higher correlation coefficients $\left(R^{2}\right)$ indicating better fitting.

Maximum methane production rate $\left(\mu_{\mathrm{m}}\right)$ varied significantly $(2.56-8.07 \mathrm{~mL} /(\mathrm{gVS} \mathrm{h}))$ due to differences in FW compositions. Higher $\mu_{\mathrm{m}}$ values were achieved for FW with higher carbohydrate content due to its rapid degradation rate, and the highest $\mu_{\mathrm{m}}$ values were achieved from $\mathrm{FW}$ with $\mathrm{CA}-\mathrm{CP}-\mathrm{EE}$ ratios ranging from 1.89 to 2.06. The lag phase usually occurs for microorganisms to acclimatise to a new environment in batch digestion experiments (Kafle and Kim, 2013; Koch et al., 2015; Noike et al., 1985). In this study, the lag time $(\lambda)$ was negligible for all the samples (Table 2), indicating immediate methane production after the AD process began. This was likely to be due to inoculum with high methanogenic activity that was collected from a stable, working FW treatment plant, and the high inoculum-to-feed ratio (especially for the inoculum-to-lipid ratio) for feedstock used in this study. Therefore, the source of an inoculum could also affect digestion characteristics (e.g. degradation rate, biogas production rate and digestion duration). High lipid concentrations could cause some operational challenges (such as mass transfer limitations, inhibition of methanogenic archaea, sludge floating) (Alves et al., 2009), therefore, higher lipid content corresponded to a longer effective biogas production period $\left(t_{\mathrm{ef}}\right)$, varying from 196 to 409 h $(p<0.05)$.

The highest value $\left(0.49 \mathrm{~d}^{-1}\right)$ of the hydrolysis constant $(k)$ was obtained from FW 
with a CA-CP-EE ratio of 2.06. There was little change in the $k$ values for FW with the same percentage of CP/EE ratios of 0.9: $1\left(0.27-0.28 \mathrm{~h}^{-1}\right)$ and methane yields (530-541 mL/gVS), such as a CA-CP-EE ratio of 2.2: 0.9: 1, 1.9: 0.9: 1 and 1.4: 0.9: 1. There was no statistically significant relationship between the three organic compounds and $k$, but was positively correlated with $\mu_{\mathrm{m}}(p<0.01)$. These correlations were accurately described by a linear model $\left(k=0.050 \mu_{\mathrm{m}}+0.034\left(R^{2}=0.9930\right)\right)$. Overall, the samples with lower lipid content resulted in a kinetic improvement (e.g., $\mu_{\mathrm{m}}$ and $k$ ), which could be a consequence of inhibition attenuation, resulting in lower concentration and less inhibitory effects by LCFA. These results also suggest that increasing either carbohydrate or protein content in FW could relieve inhibition by LCFA and stimulate degradation efficiency. Previous studies found that methane production could be recover by adding glucose and/or cysteine to digesters completely inhibited by Oleate (Kuang et al., 2006) and concluded that a combination of glucose and cysteine had a greater effect on this recovery than adding either glucose and cysteine alone. In this study, none of the digesters were completely or slightly inhibited, therefore, increasing carbohydrate content could be the most effective way of assisting kinetic performance.

$k$ was significantly, negatively correlated with $t_{\mathrm{ef}}(p<0.05)$ and methane production $(p<0.05)$, therefore, higher methane yields were achieved at longer $t_{\mathrm{ef}}$ but lower $\mu_{\mathrm{m}}$ and $k$ values. In addition, maintaining an appropriate range of lipid content in FW $(4.7-5.5 \%)$ resulted in a moderate hydrolysis rate $\left(0.27-0.36 \mathrm{~d}^{-1}\right)$ and methane yield 
rates (5.57-6.98 mL/(g VS h)), higher lipid reduction (about 78\%) and higher methane yield (530-548 mL/gVS). Under these conditions, the lowest digestion duration was achieved (196-212 h), which was 15-48\% less than the other assays in this study, and more economical benefits could be achieved. Table 2 .

\subsection{Digestate characteristics}

\subsubsection{TS and VS concentration and reduction}

The final TS content ranged from $5.4 \%$ to $6.3 \%$, while the final VS content was 50.9-56.8\% (TS \%) (Fig. 3). Decomposition of organic compounds dominantly occurred during the first 2-3 days of the digestion, and reduction ranges of 55-61\% and 65-70\% were achieved for TS and VS, respectively. These findings can be verified by the intense release of VFA during the initial period of digestion (Fig. 1b). FW with lower $\mathrm{CA}-\mathrm{CP}-\mathrm{EE}$ and $\mathrm{C} / \mathrm{N}$ ratios had lower final concentrations and reductions of TS and VS. Fig. 3.

\subsubsection{Lipid concentration and reduction}

As presented in Fig. 4a, the total concentrations of lipids in $\mathrm{FW}\left(E E_{T}\right)$ showed little variation $(5-7 \%, \%$ TS) during the initial three days, followed by a sharp decrease to its lowest values on day 5 for $\mathrm{FW}$ with a CA-CP-EE ratio of 1.89-3.0 (Group A), or day 7 for FW with a CA-CP-EE ratio of 0.36-1.6 (Group B). The lipid concentrations for Group $A$ increased to a peak on the 15 th day, and were maintained at a steady concentration from day 22 of the process. For Group $B$, the second peak occurred on day 11 , before reaching steady concentrations from day 15 . These findings could 
explain the phenomenon of the two VFA peaks for feedstock with CA-CP-EE ratios lower than 1.89 during this period. The final lipid concentrations in the solid phase of $\mathrm{FW}\left(E E_{S}\right)$ ranged from $5.5 \%$ to $6.4 \%$ (\% TS), indicating that lower lipid concentrations of FW occur with higher CA/EE ratios (Fig. $\mathbf{4 b})$.

The final reductions of $E E_{T}$ and $E E_{S}$ were within $67-87 \%$ and $80-86 \%$ respectively (Fig. 4 c and Fig. 4 d). Of the three organic components, only lipids were found to be the main factor that positively influenced $E E_{T}$ reduction $(p<0.01)$. Significant positive correlations were found between $E E_{S}$ reduction and protein $(p<0.01)$ and lipid content $(p<0.05)$, while a negative relationship was observed with carbohydrate $(p<0.01)$, for example, for FW with lipid content of $26.57-43.28 \%$ (TS basis). $E E_{S}$ reduction had a significant, positive relationship with TAN $(p<0.05)$ and FAN $(p<0.01)$. These relationships could confirm that solubilisation and bioconversion efficiency of lipids is higher under alkaline conditions. Significant, positive correlations were obtained between the maximum VFA concentrations and its compositions. This could be because, under alkaline conditions (e.g. high TAN or FAN), fatty acids in an ionic form can not pass through the lipid bilayer, thus leading to the accumulation of VFA outside the cell. Interestingly, no such relationship was observed for the reduction of $E E_{T}$, which could have been due to the calculation methods: a certain amount of fatty acids hydrolysed from the solid phase of FW had not been converted to biogas, resulting in a delay in the reduction of $E E_{T}$. These findings suggest that only considering the reduction of organics does not effectively reflect the extent of their degradation 
efficiency in FW, therefore, their final concentration and removal efficiency in both the solid phase and total FW should be investigated. Fig. 4.

\subsubsection{Protein concentration and reduction}

As shown in Fig. 5, final protein content (dry basis) varied from $16 \%$ to $23 \%$ in the solid phase of $\mathrm{FW}\left(C P_{S}\right)$, and for the total $\mathrm{FW}\left(C P_{T}\right)$. Protein initially degraded rapidly in the first 3-5 days of the process, and reductions of $41.7-59.9 \%$ and $13.1-27.2 \%$ were achieved for $C P_{T}$ and $C P_{S}$, respectively. A slower degradation process then followed, suggesting rapid reduction of easily-degradable proteins and lower hydrolysis at a low $\mathrm{pH}$ and high lipid content. Similar results were reported in other studies (Shao et al., 2013). After 30 days of digestion, reductions of 53-60\% and 44-60\% were achieved for $C P_{T}$ and $C P_{S}$, respectively.

As high protein content correlated with high TAN concentration $(p<0.01)$, more proteins needed to be solubilised and degraded to achieve higher TAN concentrations, showing higher protein reduction $(p<0.01)$. Glucose, the main hydrate of carbohydrates, could repress the formation of protease, which is responsible for decomposing protein to amino acids (Breure et al., 1986), so carbohydrate had a negative relationship with total protein reduction in $\mathrm{FW}(p<0.01)$. Additionally, methane yield was positively correlated with lipid reduction $(p<0.01)$, while protein did not have any significant effect on it. Fig. 5.

Previous studies reported that lipid hydrolysis only occurred under methanogenic conditions (Miron et al., 2000) and was slower than protein and carbohydrate 
hydrolysis (Pavlostathis and Giraldo Gomez, 1991). Considering that lipids have high solubility under an alkaline environment (Dahiya et al., 2015), it could be concluded higher reduction of $C P_{T}$ correlated with a higher reduction of $E E_{S}(p<0.01)$.

Additionally, previous studies (McInerney, 1988) reported that iso/n-Valeric acid was the main product of protein degradation. In this study, higher lipid reduction of solid phases was associated with higher concentrations of $\mathrm{n}$-Valeric and iso-Valeric acid, while total protein reduction was achieved with higher levels of iso-Valeric acid.

\subsubsection{Various COD distributions}

After 30 days of digestion, chemical oxygen demand (COD) in the digester could be split into four parts based on different existential states: a) some remaining particulate biopolymers, including carbohydrates, proteins and lipids; b) hydrolysates, including small molecular materials and soluble organic substrates (e.g., LCFA, amino acids and simple sugars; c) VFA and ethanol, which could be converted to methane; and d) organics, which had already been used for methane production.

As shown in Fig. 5e, 78-86\% of the COD present in FW were converted to methane by the end of the digestion process. In the influent, $6-15 \%$ of the hydrolysates COD and $6-11 \%$ of the particulate biopolymer COD were present. There were very small percentages of VFA and ethanol COD present (0.01-0.04\%). The bioconversion efficiency of COD to methane had a significant, positive correlation with carbohydrate content $(p<0.05)$ and a negative correlation with protein content $(p<0.01)$ in feedstock. A significant, positive relationship was found between hydrolysates COD 
and protein content $(p<0.05)$, while carbohydrate had a significant negative relationship $(p<0.01)$. Lipid had a significant negative correlation with particulate biopolymer COD, while the other two organics had no effect. All three organics had no correlation with VFA and ethanol COD $(p>0.05)$.

The final accumulation of VFA and LCFA was related to the final equilibrium of the digestion system, which suggested that the methanogenesis step had failed, and provided more specific information about the process' behaviour. Based on the findings of this study, controlling the $\mathrm{CA}-\mathrm{CP}-\mathrm{EE}$ ratios to be higher than 1.89 (with carbohydrate content higher than $8.3 \%$, protein lower than $5.0 \%$, and lipid lower than $5.6 \%$ ) could be an effective way to maintain high methane yields and process stability.

\subsection{Relationships among digestion performance parameters}

A PCA was carried out on different chemical components and performance parameters that could affect the biodegradation and biomethane yield of FW. The PCA results for all the FW samples indicated that three significant components were extracted, explaining $100 \%$ of the total variance in the matrix (Table 3). The first factor (accounting for $52.4 \%$ of the total variance) was characterised by very high loadings of $\mathrm{CA}-\mathrm{CP}-\mathrm{EE}$, maximum concentrations of acetic and iso-Valeric acid, final TAN concentration and the reduction of TS and proteins, contributing to steady digestion and high methane yield. The second factor (accounting for $28.4 \%$ of the total variance) was mainly associated with very high loadings of maximum $\mathrm{pH}$ values and protein reduction in the solid phase of $\mathrm{FW}$, and with moderate loadings of the 
hydrolysis constant and VS reduction. This factor accounts for the increased alkalinity of the digestion microenvironment in the digestion system. Factor 3 was characterized by the dominance of only one variable (maximum n-Valeric concentration). Cluster analysis grouped the variables into four major distinct clusters; cluster A, B, C, and D (Fig. 6). Clusters A and D, B, and C, correspond to factors 1, 2, and 3, of the PCA, respectively (Table 3). The similarity of cluster analysis to PCA confirms the interpretations drawn from the PCA.

Based on the Pearson correlation analysis and PCA, the maximum concentrations of propionic acid and total VFA were closer and more correlated with the other variables grouped in the Cluster A. For FW, high hydrolysis rates $(k)$ correspond with high $\mu_{\mathrm{m}}$, low $t_{e f}$ and low methane yield, thus, appropriate organics hydrolysis could lead to high methane production. The maximum concentrations of VFA and propionic acid were significantly, positively correlated with the variables, and had a moderate correlation with the maximum iso-Butyric acid concentration in Cluster A. Thus, higher VFA and propionic acid concentrations indicate higher buffering capacity, protein reduction and methane production, however, high concentrations of VFA or propionic acid do not necessarily indicate that the AD process is balanced, due to positive correlations with FAN and longer digestion durations when VFA and propionic acid concentrations were lower than 1560 and $1172 \mathrm{mg} / \mathrm{L}$, respectively. Table 3. Fig. 6.

In addition, further correlations were achieved between the CA-CP-EE ratio and parameters that included digestion performance, process kinetics, and biodegradability, 
compared to those with the $\mathrm{C} / \mathrm{N}$ ratio. No significant correlation was found between the $\mathrm{C} / \mathrm{N}$ ratios and the maximum values of $\mathrm{pH}$, VFA and propionic acid, final $\mathrm{FAN}$, and EE reduction in the solid phase; however, these process parameters, which had major influences on digestion performance and were monitored frequently, had a significant relationship with the CA-CP-EE ratio. A significant correlation was found between these two ratios, and greater similarity was exhibited based on the cluster analysis due to lower Euclidean distance (Fig. 6). Furthermore, chemically speaking, the $\mathrm{C} / \mathrm{N}$ ratio is the ratio of the mass of carbon to the mass of nitrogen in a substance, however, only proteins contain nitrogen, while both carbohydrates and lipids contain carbon. In this case, the CA-CP-EE ratio would be more appropriate when being considered as an indicator affecting digestion performance (e.g., biomethane production). In this study, FW with a CA-CP-EE ratio higher than 1.89 (CA higher than $8.3 \%, \mathrm{CP}$ lower than $5.0 \%$, and EE lower than 5.6\%) achieved better digestion performance.

\section{Conclusions}

The CA-CP-EE ratio was a critical parameter, correlating with performance parameters, thus affecting methane yield and final reduction of organics. Controlling the CA-CP-EE ratio higher than 1.89 (CA higher than 8.3\%, CP lower than 5.0\%, and EE lower than 5.6\%) maintained stable digestion with higher methane production (385-627 mL/gVS), shorter digestion retention (196-409 h), and a methane bioconversion efficiency of COD (78-86\%). The CA-CP-EE ratio could be used as an important indicator for digestion performance. To effectively evaluate organic 
reduction, the removal efficiency of organics in both the solid phase and the total FW

should be considered.

E-supplementary data for this work can be found in e-version of this paper online.

\section{Acknowledgements}

This work was supported by the China Scholarship Council (CSC No. 201606210435).

\section{References}

1. Alibardi, L., Cossu, R., 2016. Effects of carbohydrate, protein and lipid content of organic waste on hydrogen production and fermentation products. Waste Management, 47, 69-77.

2. Alves, M.M., Pereira, M.A., Sousa, D.Z., Cavaleiro, A.J., Picavet, M., Smidt, H., Stams, A.J., 2009. Waste lipids to energy: how to optimize methane production from long - chain fatty acids (LCFA). Microbial Biotechnology, 2, 538-550.

3. American, P.H.A., American, W.W.A., Water, P.C.F., Water, E.F., 1915. Standard methods for the examination of water and wastewater. American Public Health Association.

4. Angelidaki, I., Sanders, W., 2004. Assessment of the anaerobic biodegradability of macropollutants. Reviews in Environmental Science and Biotechnology, 3, 117-129.

5. Astals, S., Batstone, D.J., Mata-Alvarez, J., Jensen, P.D., 2014. Identification of synergistic impacts during anaerobic co-digestion of organic wastes. Bioresource Technology, 169, 421-427.

6. Breure, A.M., Mooijman, K.A., Van Andel, J.G., 1986. Protein degradation in anaerobic digestion: influence of volatile fatty acids and carbohydrates on hydrolysis and acidogenic fermentation of gelatin. Applied Microbiology and Biotechnology, 24, 426-431.

7. Brown, D., Li, Y., 2013. Solid state anaerobic co-digestion of yard waste and food waste for biogas production. Bioresource Technology, 127, 275-280.

8. Cho, J.K., Park, S.C., Chang, H.N., 1995. Biochemical methane potential and solid state anaerobic digestion of Korean food wastes. Bioresource Technology, 52, 245-253.

9. Cirne, D.G., Paloumet, X., Bj Rnsson, L., Alves, M.M., Mattiasson, B., 2007. Anaerobic digestion of lipid-rich waste-Effects of lipid concentration. Renewable Energy, 32, 965-975.

10. Dahiya, S., Sarkar, O., Swamy, Y.V., Mohan, S.V., 2015. Acidogenic fermentation of food waste for volatile fatty acid production with co-generation of biohydrogen. Bioresource Technology, 182, 103-113.

11. De Gioannis, G., Muntoni, A., Polettini, A., Pomi, R., 2013. A review of dark fermentative hydrogen production from biodegradable municipal waste fractions. Waste Management, 33, 1345-1361.

12. Donoso-Bravo, A., Pérez-Elvira, S.I., Fdz-Polanco, F., 2010. Application of simplified models for anaerobic biodegradability tests. Evaluation of pre-treatment processes. Chemical Engineering Journal, 160, 607-614.

13. Jin, Y., Chen, T., Chen, X., Yu, Z., 2015. Life-cycle assessment of energy consumption and environmental impact of an integrated food waste-based biogas plant. Applied Energy, 151, 227-236.

14. Jones Jr, J.B., 1991. Kjeldahl method for nitrogen determination. Kjeldahl method for nitrogen determination.

15. Kafle, G.K., Kim, S.H., 2013. Anaerobic treatment of apple waste with swine manure for biogas production: Batch and continuous operation. Applied Energy, 103, 61-72.

16. Kobayashi, T., Xu, K., Li, Y., Inamori, Y., 2012. Evaluation of hydrogen and methane production from municipal solid wastes with different compositions of fat, protein, cellulosic materials and the other 
carbohydrates. International Journal of Hydrogen Energy, 37, 15711-15718.

17. Koch, K., Helmreich, B., Drewes, J.R.E., 2015. Co-digestion of food waste in municipal wastewater treatment plants: Effect of different mixtures on methane yield and hydrolysis rate constant. Applied Energy, 137, 250-255.

18. Kuang, Y., Pullammanappallil, P., Lepesteur, M., Ho, G.E., 2006. Recovery of oleate - inhibited anaerobic digestion by addition of simple substrates. Journal of Chemical Technology and Biotechnology, 81, 1057-1063.

19. Langrish, T.A., Handbook of Nutraceuticals Volume II Scale-Up, Processing and Automation. 20. Li, L., Kong, X., Yang, F., Li, D., Yuan, Z., Sun, Y., 2012. Biogas production potential and kinetics of microwave and conventional thermal pretreatment of grass. Applied Biochemistry and Biotechnology, 166, 1183-1191.

21. Li, Y., Jin, Y., Li, J., Li, H., Yu, Z., 2016. Effects of pungency degree on mesophilic anaerobic digestion of kitchen waste. Applied Energy, 181, 171-178.

22. Lin, J., Zuo, J., Gan, L., Li, P., Liu, F., Wang, K., Chen, L., Gan, H., 2011. Effects of mixture ratio on anaerobic co-digestion with fruit and vegetable waste and food waste of China. JOURNAL OF ENVIRONMENTAL SCIENCES, 23, 1403-1408.

23. Mata-Alvarez, J., Dosta, J., Romero-Güiza, M.S., Fonoll, X., Peces, M., Astals, S., 2014. A critical review on anaerobic co-digestion achievements between 2010 and 2013. Renewable and Sustainable Energy Reviews, 36, 412-427.

24. Mawson, A.J., Earle, R.L., Larsen, V.F., 1991. Degradation of acetic and propionic acids in the methane fermentation. Water Research, 25, 1549-1554.

25. McInerney, M.J., 1988. Anaerobic hydrolysis and fermentation of fats and proteins. Biology of anaerobic microorganisms, 38, 373-415.

26. Miron, Y., Zeeman, G., Van Lier, J.B., Lettinga, G., 2000. The role of sludge retention time in the hydrolysis and acidification of lipids, carbohydrates and proteins during digestion of primary sludge in CSTR systems. Water Research, 34, 1705-1713.

27. Noike, T., Endo, G., Chang, J.E., Yaguchi, J.I., Matsumoto, J.I., 1985. Characteristics of carbohydrate degradation and the rate - limiting step in anaerobic digestion. Biotechnology and Bioengineering, 27, 1482-1489.

28. Pagliaccia, P., Gallipoli, A., Gianico, A., Montecchio, D., Braguglia, C.M., 2016. Single stage anaerobic bioconversion of food waste in mono and co-digestion with olive husks: Impact of thermal pretreatment on hydrogen and methane production. International Journal of Hydrogen Energy, 41, 905-915.

29. Paritosh, K., Kushwaha, S.K., Yadav, M., Pareek, N., Chawade, A., Vivekanand, V., 2017. Food Waste to Energy: An Overview of Sustainable Approaches for Food Waste Management and Nutrient Recycling. Biomed Research International, 2017.

30. Pavlostathis, S.G., Giraldo Gomez, E., 1991. Kinetics of anaerobic treatment: a critical review. Critical Reviews in Environmental Science and Technology, 21, 411-490.

31. Rajagopal, R., Massé, D.I., Singh, G., 2013. A critical review on inhibition of anaerobic digestion process by excess ammonia. Bioresource Technology, 143, 632-641.

32. Shao, L., Wang, T., Li, T., Lü, F., He, P., 2013. Comparison of sludge digestion under aerobic and anaerobic conditions with a focus on the degradation of proteins at mesophilic temperature. Bioresource Technology, 140, 131-137. 
33. Siles, J.A., Brekelmans, J., Martin, M.A., Chica, A.F., Martin, A., 2010. Impact of ammonia and sulphate concentration on thermophilic anaerobic digestion. Bioresource Technology, 101, 9040-9048.

34. Sun, Y., Wang, D., Yan, J., Qiao, W., Wang, W., Zhu, T., 2014. Effects of lipid concentration on anaerobic co-digestion of municipal biomass wastes. Waste Management, 34, 1025-1034.

35. Tang, Y., Koike, Y., Liu, K., An, M., Morimura, S., Wu, X., Kida, K., 2008. Ethanol production from kitchen waste using the flocculating yeast Saccharomyces cerevisiae strain KF-7. Biomass and Bioenergy, 32, 1037-1045.

36. Wagner, A.O., Lins, P., Malin, C., Reitschuler, C., Illmer, P., 2013. Impact of protein-, lipid-and cellulose-containing complex substrates on biogas production and microbial communities in batch experiments. Science of the Total Environment, 458, 256-266.

37. Wan, C., Zhou, Q., Fu, G., Li, Y., 2011. Semi-continuous anaerobic co-digestion of thickened waste activated sludge and fat, oil and grease. Waste Management, 31, 1752-1758.

38. Wang, K., Yin, J., Shen, D., Li, N., 2014. Anaerobic digestion of food waste for volatile fatty acids (VFAs) production with different types of inoculum: effect of pH. Bioresource Technology, 161, 395-401.

39. Wyman, C., 1996. Handbook on bioethanol: production and utilization. CRC press.

40. Xie, S., Hai, F.I., Zhan, X., Guo, W., Ngo, H.H., Price, W.E., Nghiem, L.D., 2016. Anaerobic co-digestion: A critical review of mathematical modelling for performance optimization. Bioresource Technology, 222, 498-512.

41. Yang, G., Zhang, P., Zhang, G., Wang, Y., Yang, A., 2015. Degradation properties of protein and carbohydrate during sludge anaerobic digestion. Bioresource Technology, 192, 126-130.

42. Yin, J., Wang, K., Yang, Y., Shen, D., Wang, M., Mo, H., 2014. Improving production of volatile fatty acids from food waste fermentation by hydrothermal pretreatment. Bioresource Technology, 171, 323-329.

43. Yuan, H., Zhu, N., 2016. Progress in inhibition mechanisms and process control of intermediates and by-products in sewage sludge anaerobic digestion. Renewable and Sustainable Energy Reviews, 58, 429-438.

44. Zhang, B., Zhang, L.L., Zhang, S.C., Shi, H.Z., Cai, W.M., 2005. The influence of pH on hydrolysis and acidogenesis of kitchen wastes in two-phase anaerobic digestion. Environmental Technology, 26, 329-340.

45. Zhang, C., Su, H., Baeyens, J., Tan, T., 2014. Reviewing the anaerobic digestion of food waste for biogas production. Renewable and Sustainable Energy Reviews, 38, 383-392.

46. Zhang, C., Xiao, G., Peng, L., Su, H., Tan, T., 2013. The anaerobic co-digestion of food waste and cattle manure. Bioresource Technology, 129, 170-176.

47. Zhang, L., Lee, Y., Jahng, D., 2011. Anaerobic co-digestion of food waste and piggery wastewater: focusing on the role of trace elements. Bioresource Technology, 102, 5048-5059.

48. Zhang, R., El-Mashad, H.M., Hartman, K., Wang, F., Liu, G., Choate, C., Gamble, P., 2007. Characterization of food waste as feedstock for anaerobic digestion. Bioresource Technology, 98, 929-935. 
2 Table 1 (a). Characteristics of FW compositions for the AD experiments.

\begin{tabular}{|c|c|c|c|c|c|c|c|c|c|c|c|}
\hline Parameters & No. 1 & No. 2 & No. 3 & No. 4 & No. 5 & No. 6 & No. 7 & No. 8 & No. 9 & No. 10 & No. 11 \\
\hline TS (\%) & 19.1 & 17.2 & 20.5 & 19.7 & 19.6 & 20.0 & 20.8 & 19.2 & 20.9 & 24.7 & 18.7 \\
\hline VS (\% TS) & 97.0 & 97.2 & 96.5 & 96.7 & 96.5 & 96.3 & 95.9 & 96.1 & 95.8 & 95.2 & 95.3 \\
\hline $\mathrm{CA}^{\mathrm{a}}(\%)$ & 10.8 & 9.4 & 11.0 & 10.1 & 9.3 & 9.2 & 8.3 & 7.6 & 7.7 & 8.1 & 3.1 \\
\hline $\mathrm{CP}^{\mathrm{b}}(\%)$ & 4.0 & 4.5 & 3.6 & 4.3 & 4.6 & 4.6 & 5.0 & 5.2 & 5.3 & 5.3 & 7.9 \\
\hline $\mathrm{EE}^{\mathrm{c}}(\%)$ & 3.7 & 2.9 & 5.3 & 4.7 & 5.0 & 5.5 & 6.6 & 5.6 & 7.1 & 10.2 & 6.9 \\
\hline $\mathrm{C}(\% \mathrm{TS})$ & 45.5 & 45.6 & 46.9 & 46.5 & 47.1 & 47.5 & 48.8 & 48.4 & 49.4 & 51.5 & 51.5 \\
\hline $\mathrm{H}(\% \mathrm{TS})$ & 6.8 & 6.8 & 7.1 & 7.0 & 7.0 & 7.1 & 7.3 & 7.2 & 7.4 & 7.7 & 7.5 \\
\hline $\mathrm{N}(\% \mathrm{TS})$ & 2.6 & 3.4 & 2.6 & 2.8 & 3.1 & 3.1 & 3.3 & 3.8 & 3.5 & 2.9 & 5.3 \\
\hline $\mathrm{C} / \mathrm{N}$ & 17.7 & 13.4 & 17.8 & 16.8 & 15.4 & 15.5 & 14.7 & 12.7 & 14.0 & 18.1 & 9.7 \\
\hline $\mathbf{C A}-\mathbf{C P}-\mathbf{E E}$ & 2.9:1.1:1 & 3.3:1.6:1 & 2.1:0.7:1 & 2.2:0.9:1 & 1.9:0.9:1 & 1.7:0.9:1 & 1.2:0.8:1 & 1.4:0.9:1 & 1.1:0.7:1 & 0.8:0.5:1 & 0.4:1.1:1 \\
\hline
\end{tabular}

$3{ }^{\mathrm{a}} \mathrm{CA}$ : carbohydrate; ${ }^{\mathrm{b}} \mathrm{CP}$ : crude protein; ${ }^{\mathrm{c}} \mathrm{EE}$ : ether extract

4 Table 1 (b). Characteristics of the inoculum.

\begin{tabular}{ccccc}
\hline Parameter & $\mathrm{pH}$ & $\mathrm{TS}(\%)$ & $\mathrm{VS}(\%)$ & Ammonia (mg/L) \\
\hline Value & 7.34 & $3.65 \%$ & $2.42 \%$ & 1123 \\
\hline
\end{tabular}


5 Table 2. Parameters of the kinetic models obtained from the methane yield of FW with different compositions in terms of CA: CP: EE.

\begin{tabular}{|c|c|c|c|c|c|c|c|c|c|c|}
\hline \multirow{2}{*}{$\mathrm{CA}-\mathrm{CP}-\mathrm{EE}$} & \multicolumn{6}{|c|}{$B=B_{0} \times\left\{1-\exp \left[-\mu_{\mathrm{m}} \times(t-\lambda) / B_{0}\right]\right\}$} & \multicolumn{4}{|c|}{$B=B_{0} \times[1-\exp (-k t)]$} \\
\hline & $R^{2}$ & $\mu_{\mathrm{m}}(\mathrm{mL} / \mathrm{gVS} \mathrm{h})$ & $\lambda(\mathrm{h})$ & $B_{0}(\mathrm{~mL} / \mathrm{gVS})$ & $B_{0} / M^{\mathrm{a}}$ & $t_{\text {ef }}(\mathrm{h})^{\mathrm{b}}$ & $R^{2}$ & $k\left(\mathrm{~d}^{-1}\right)$ & $B_{0}(\mathrm{~mL} / \mathrm{gVS})$ & $B_{0} / M^{\mathrm{a}}$ \\
\hline 2.9:1.1:1 & 0.9845 & 2.66 & 0.00 & 536.19 & 1.05 & 343 & 0.9731 & 0.14 & 522.23 & 1.03 \\
\hline 3.3:1.6:1 & 0.9619 & 8.07 & 0.00 & 441.23 & 0.96 & 231 & 0.9587 & 0.49 & 439.84 & 0.96 \\
\hline 2.1:0.7:1 & 0.9867 & 6.04 & 0.00 & 531.30 & 0.99 & 245 & 0.9830 & 0.30 & 528.61 & 0.99 \\
\hline 2.2:0.9:1 & 0.9961 & 5.75 & 0.00 & 537.37 & 1.00 & 212 & 0.9940 & 0.27 & 535.56 & 1.00 \\
\hline 1.9:0.9:1 & 0.9958 & 5.86 & 0.00 & 533.01 & 1.01 & 202 & 0.9937 & 0.28 & 531.34 & 1.00 \\
\hline $1.7: 0.9: 1$ & 0.9870 & 6.98 & 0.00 & 544.95 & 0.99 & 196 & 0.9779 & 0.36 & 541.62 & 0.99 \\
\hline 1.2:0.8:1 & 0.9489 & 2.94 & 0.00 & 579.26 & 1.03 & 369 & 0.8830 & 0.21 & 544.22 & 0.96 \\
\hline 1.4:0.9:1 & 0.9243 & 3.33 & 0.00 & 539.13 & 1.00 & 363 & 0.8611 & 0.28 & 510.68 & 0.94 \\
\hline $1.1: 0.7: 1$ & 0.9480 & 2.72 & 0.00 & 559.92 & 1.03 & 383 & 0.8845 & 0.21 & 523.36 & 0.96 \\
\hline $0.8: 0.5: 1$ & 0.9801 & 2.56 & 0.00 & 678.23 & 1.08 & 409 & 0.9399 & 0.14 & 628.13 & 1.00 \\
\hline $0.4: 1.1: 1$ & 0.9588 & 3.89 & 0.00 & 569.06 & 0.99 & 348 & 0.9264 & 0.24 & 550.71 & 0.96 \\
\hline
\end{tabular}

$6 \quad{ }^{a} B_{0} / M$ : predicted methane production by kinetic models $\left(B_{0}\right) /$ measured methane yield during the experiment.

$7 \quad{ }^{\mathrm{b}} t_{\mathrm{ef}}$ : calculated by subtracting the lag time $(\lambda)$ from the time taken for $90 \%$ methane production ( $\left.t_{90}\right)$. 
8 Table 3. Component Matrix (extraction method: Principal Component Analysis).

\begin{tabular}{|c|c|c|c|}
\hline \multirow{2}{*}{ Items } & \multicolumn{3}{|c|}{ Principal factors } \\
\hline & 1 & 2 & 3 \\
\hline pHmin & 0.898 & 0.056 & -0.437 \\
\hline pHmax & 0.047 & 0.995 & -0.089 \\
\hline VFAmax & -0.020 & 0.703 & -0.711 \\
\hline CA-CP-EE & -0.966 & -0.255 & -0.044 \\
\hline Max. Ethanol & 0.901 & 0.423 & 0.097 \\
\hline Max. Acetic & 0.979 & -0.058 & 0.197 \\
\hline Max. Propionic & 0.093 & 0.711 & -0.697 \\
\hline Max. iso-Butyric & 0.744 & 0.572 & 0.346 \\
\hline Max. n-Butyric & 0.640 & 0.475 & 0.604 \\
\hline Max. iso-Valeric & 0.974 & 0.080 & -0.212 \\
\hline Max. n-Valeric & 0.242 & 0.237 & 0.941 \\
\hline Final ethanol & -0.668 & 0.241 & 0.704 \\
\hline Final TAN & 0.968 & 0.113 & 0.222 \\
\hline Final FAN & 0.542 & 0.797 & 0.265 \\
\hline$\mu \mathrm{m}$ & 0.949 & -0.278 & 0.149 \\
\hline$t_{e f}$ & -0.876 & 0.470 & 0.109 \\
\hline$k$ & 0.521 & -0.846 & -0.112 \\
\hline TS reduction & -0.956 & 0.241 & 0.166 \\
\hline EE reduction & -0.618 & 0.764 & -0.183 \\
\hline EE reduction in solid phase & 0.259 & 0.415 & 0.872 \\
\hline $\mathrm{CP}$ reduction & 0.972 & 0.165 & 0.164 \\
\hline $\mathrm{CP}$ reduction in solid phase & 0.295 & -0.931 & 0.215 \\
\hline$R_{\max }$ & -0.812 & 0.111 & 0.572 \\
\hline $\mathrm{C} / \mathrm{N}$ & -0.903 & 0.362 & 0.230 \\
\hline VS reduction & 0.332 & 0.832 & -0.444 \\
\hline Percentage of variance (\%) & 52.4 & 28.4 & 19.1 \\
\hline Cumulative percentage (\%) & 52.4 & 80.8 & 100 \\
\hline
\end{tabular}

9 

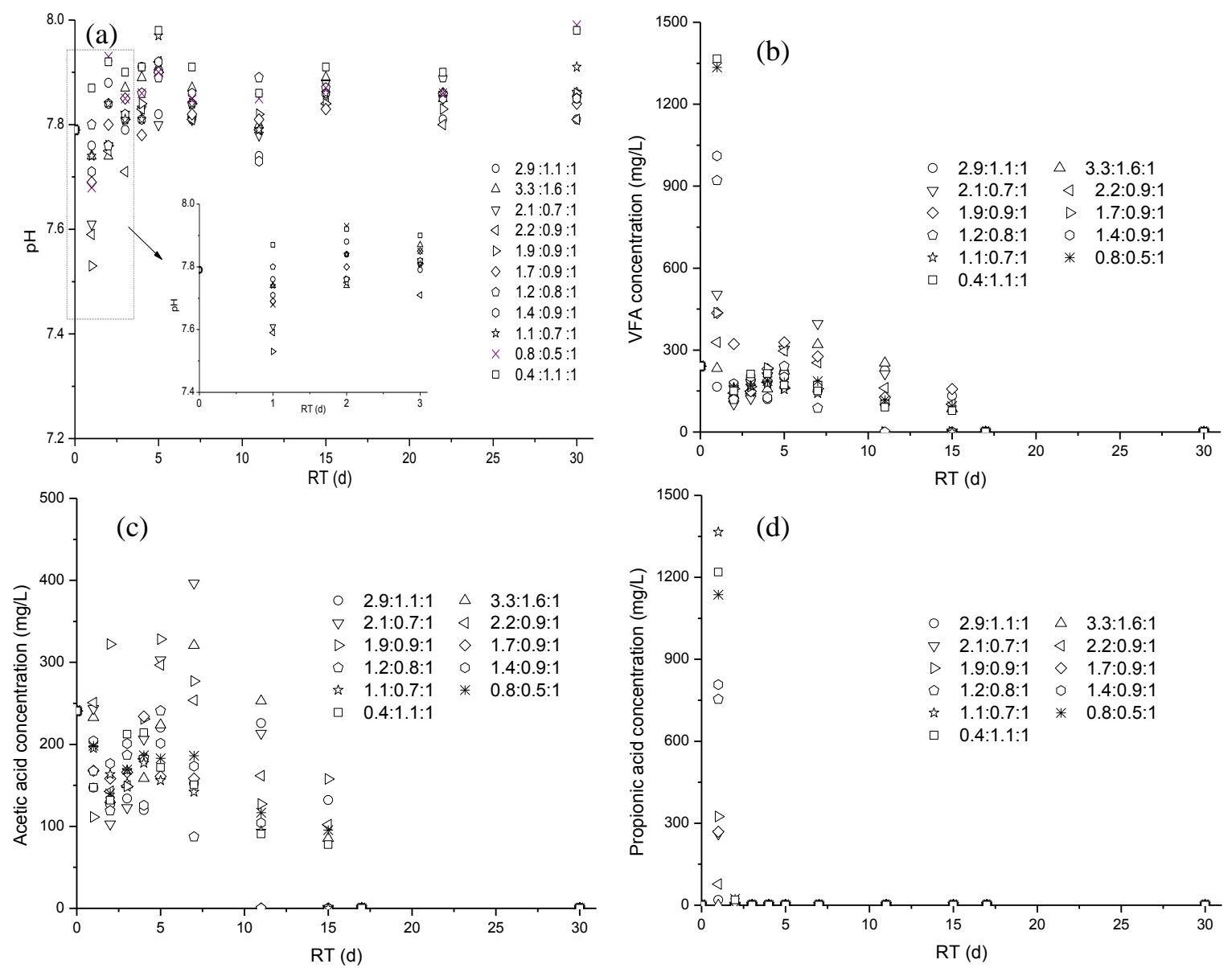

12 Fig. 1. The impact of organic compositions (CA: CP: EE) on pH (a), VFA

13 concentration (b), and VFA compositions (c, d) during the digestion of FW. 

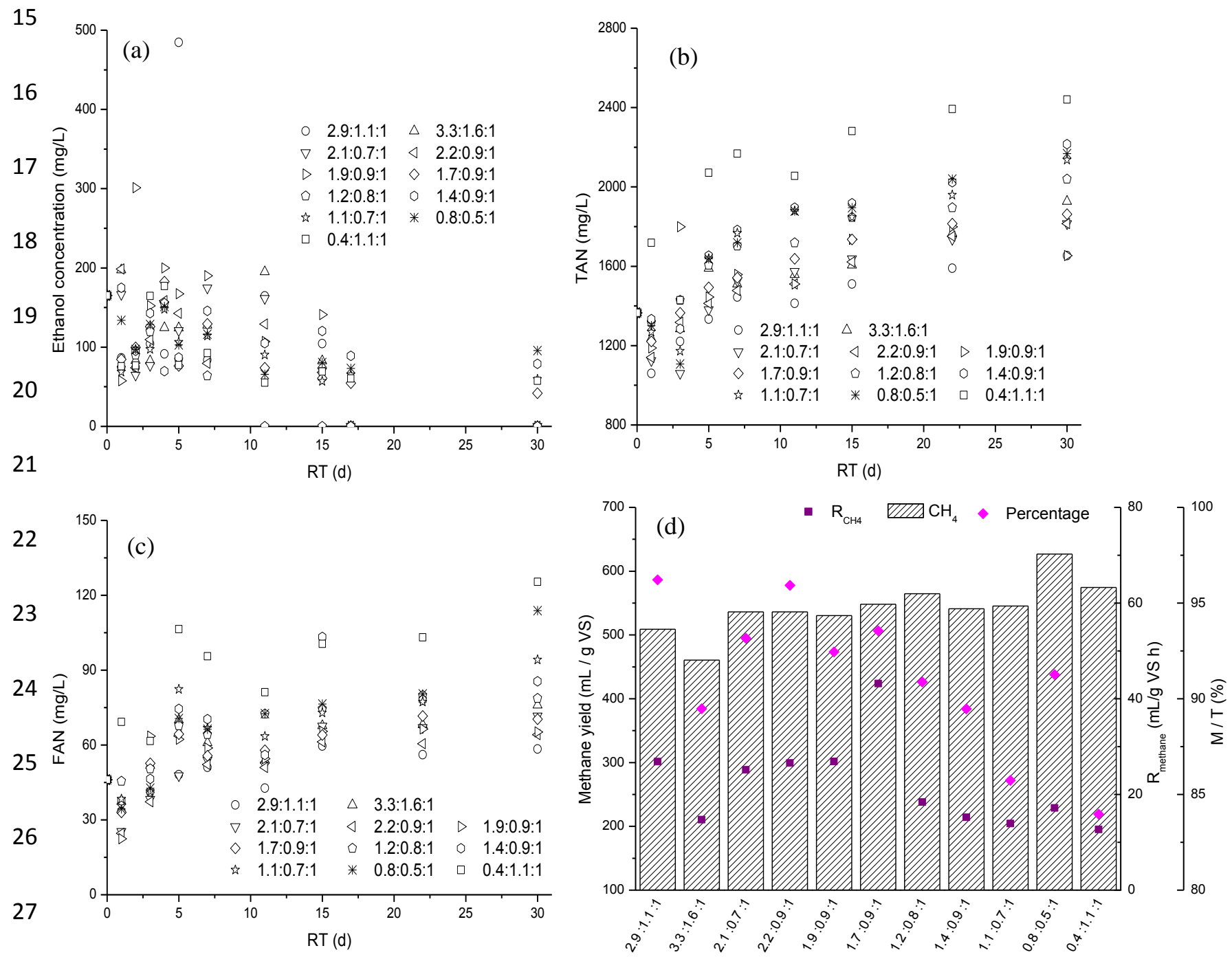

28 Fig. 2. Varying concentrations of ethanol (a), TAN (b), and FAN (c) during AD of FW

29 and the development of the final methane yields, maximum specific methane

30 production $\left(R_{\max }\right)$ and the $\mathrm{M} / \mathrm{T}$ ratio with different compositions in terms of

CA-CP-EE. 

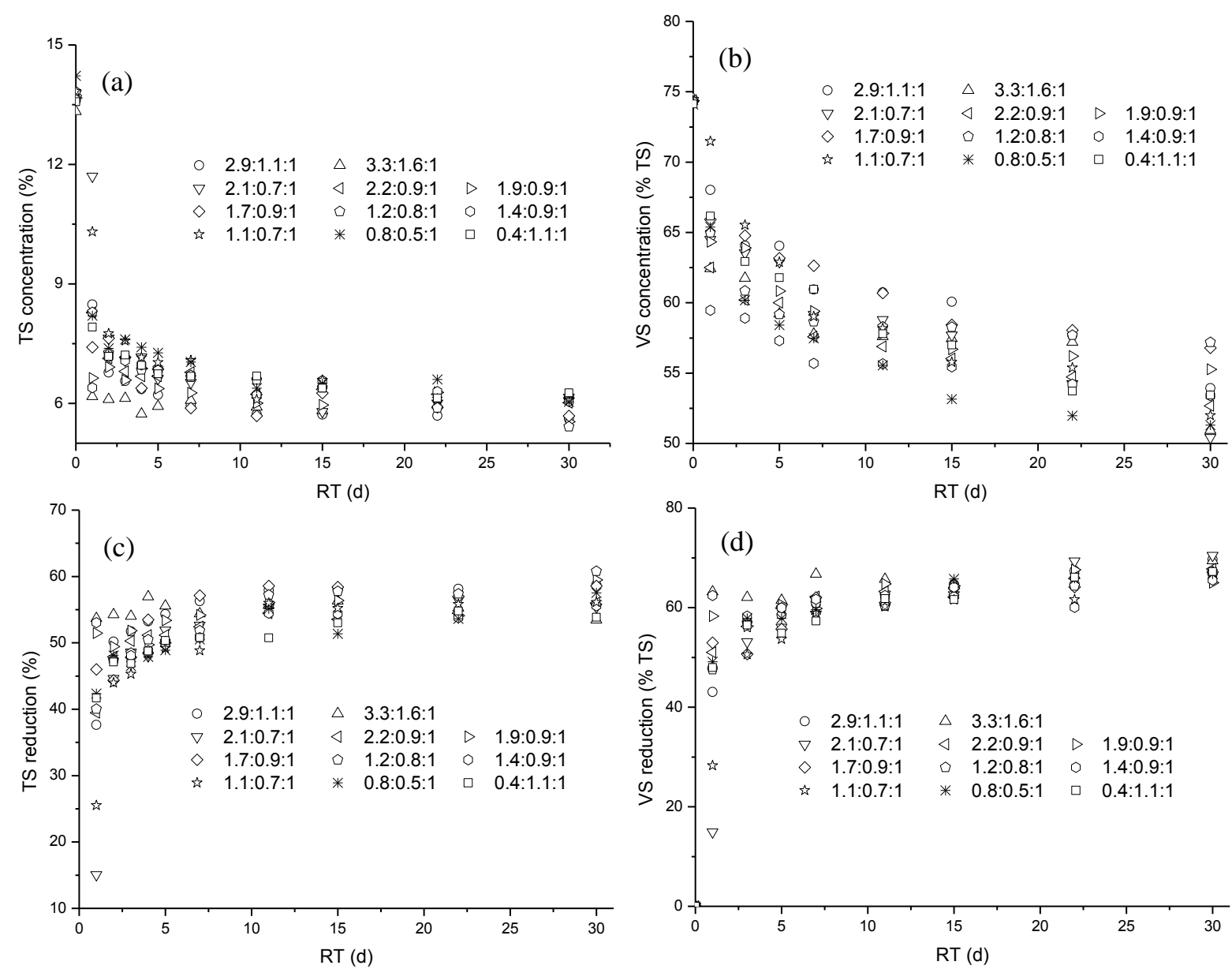

33 Fig. 3. The impact of composition (CA-CP-EE) on the concentrations of TS (a) and

34 VS (b) and the reduction of TS (c) and VS (d) during 30 days of digestion. 

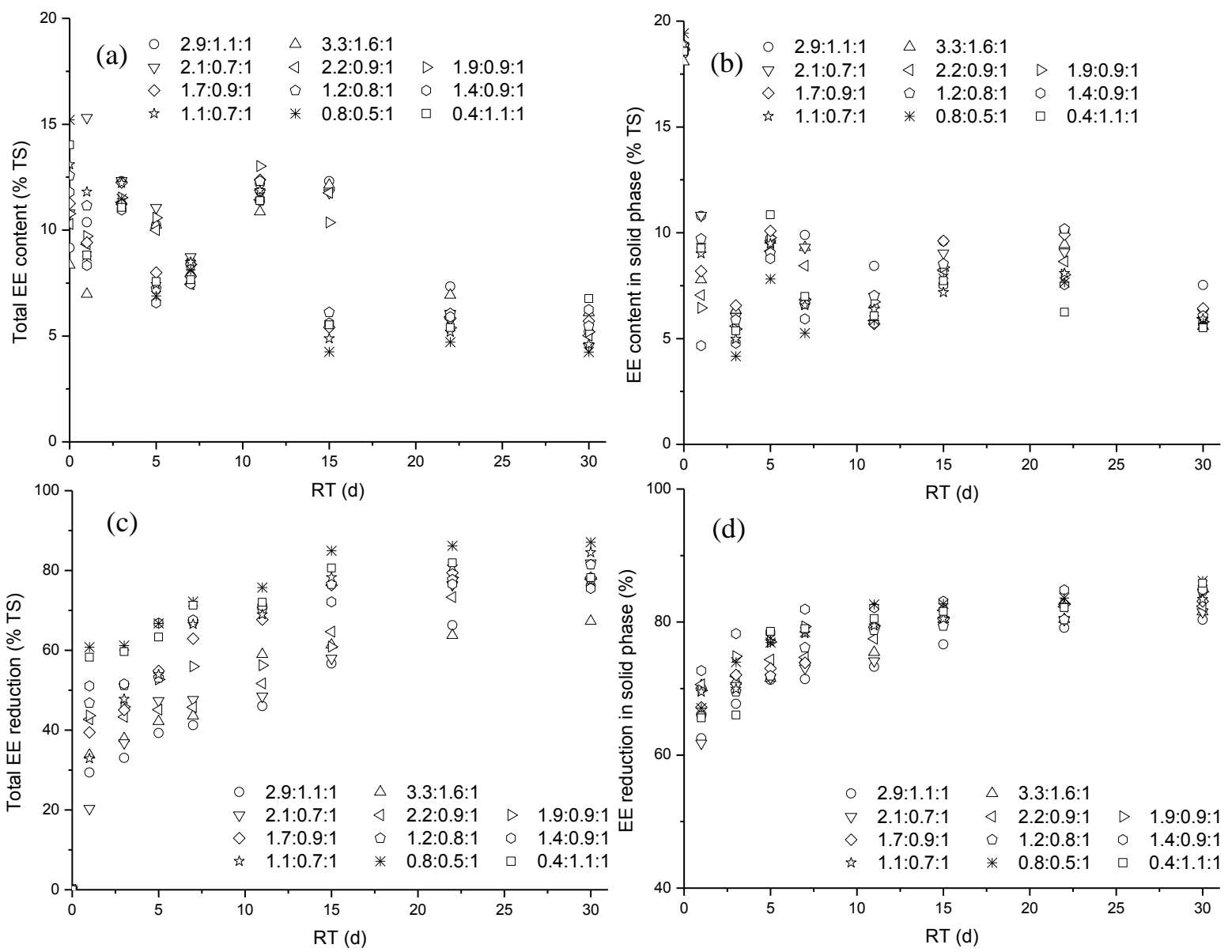

(d)

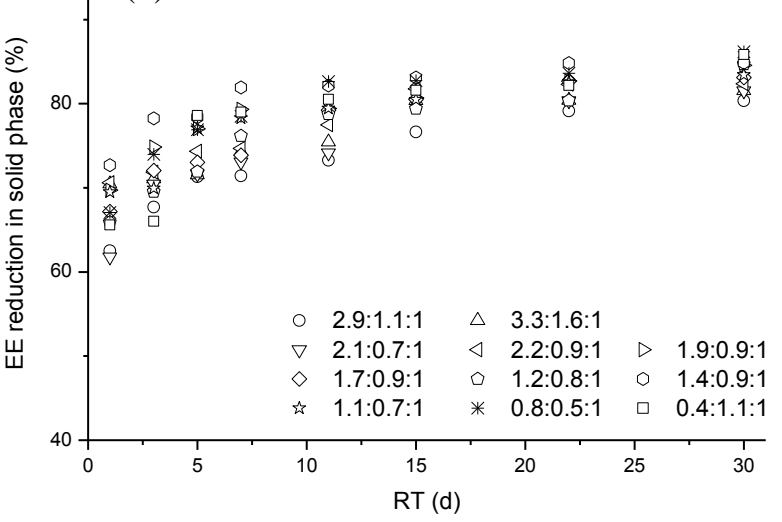

36 Fig. 4. The impact of composition (CA: CP: EE) on lipid concentrations and

37 reductions during 30 days of digestion.

38 


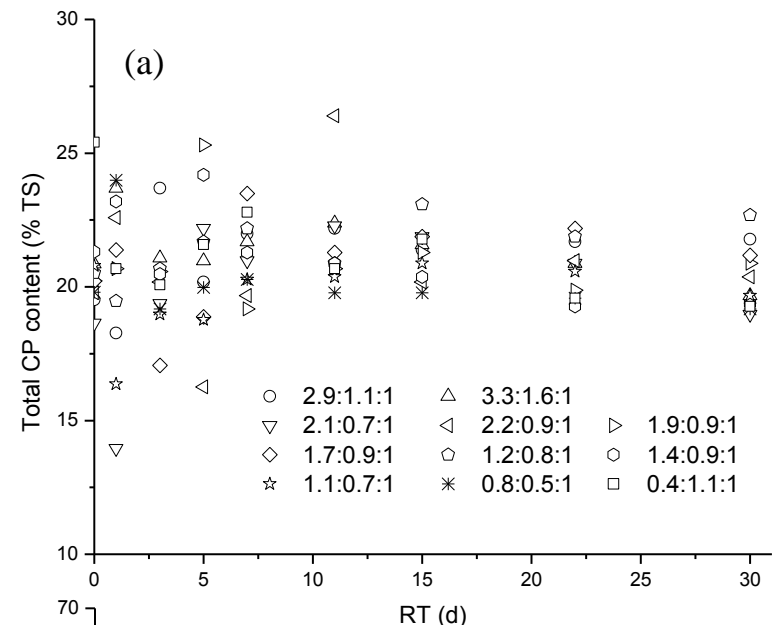

(c)

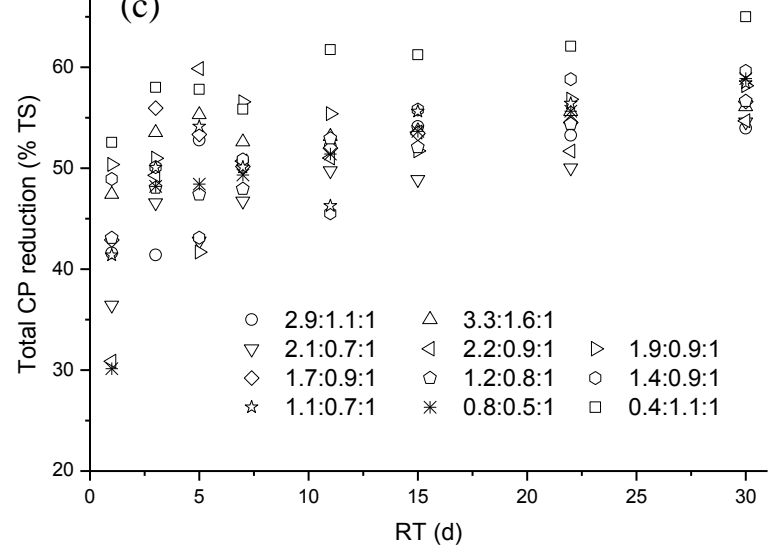

(b)

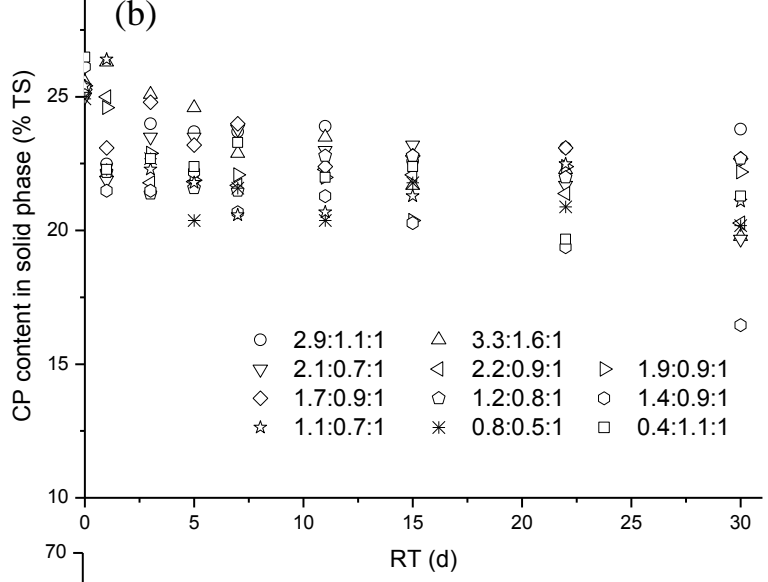

(d)
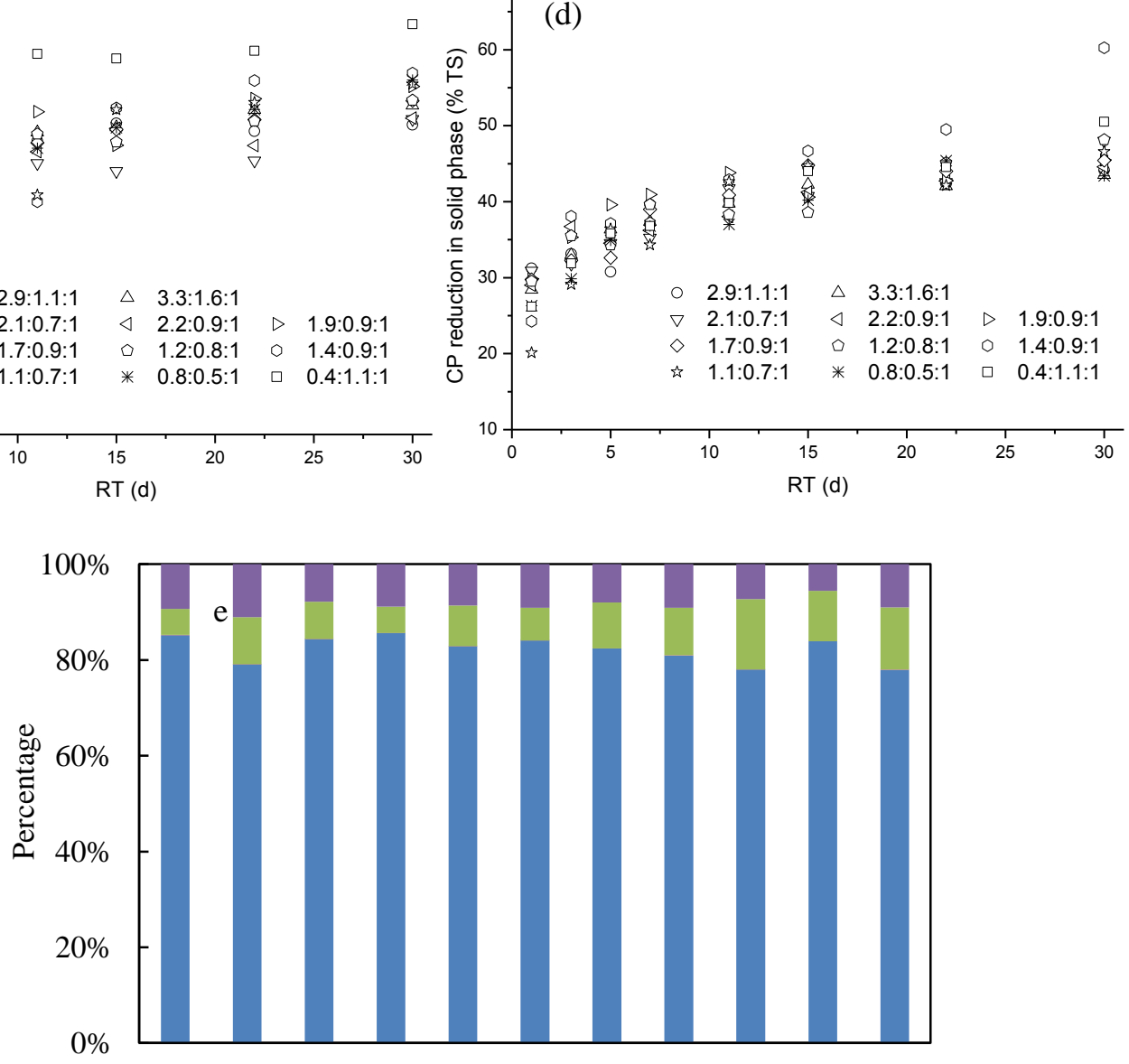

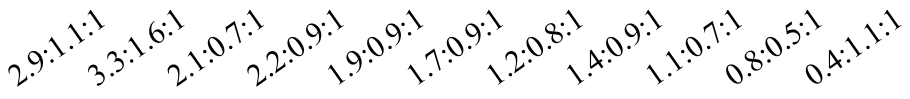

CA-CP-EE

40 Fig. 5. The impact of composition (CA: CP: EE) on the concentrations and reductions

41 of protein during 30 days of digestion (a, b, c, d); various fractions of COD as a

42 function of organic compositions at the end of digestion (e). 
Euclidean distance cluster combined

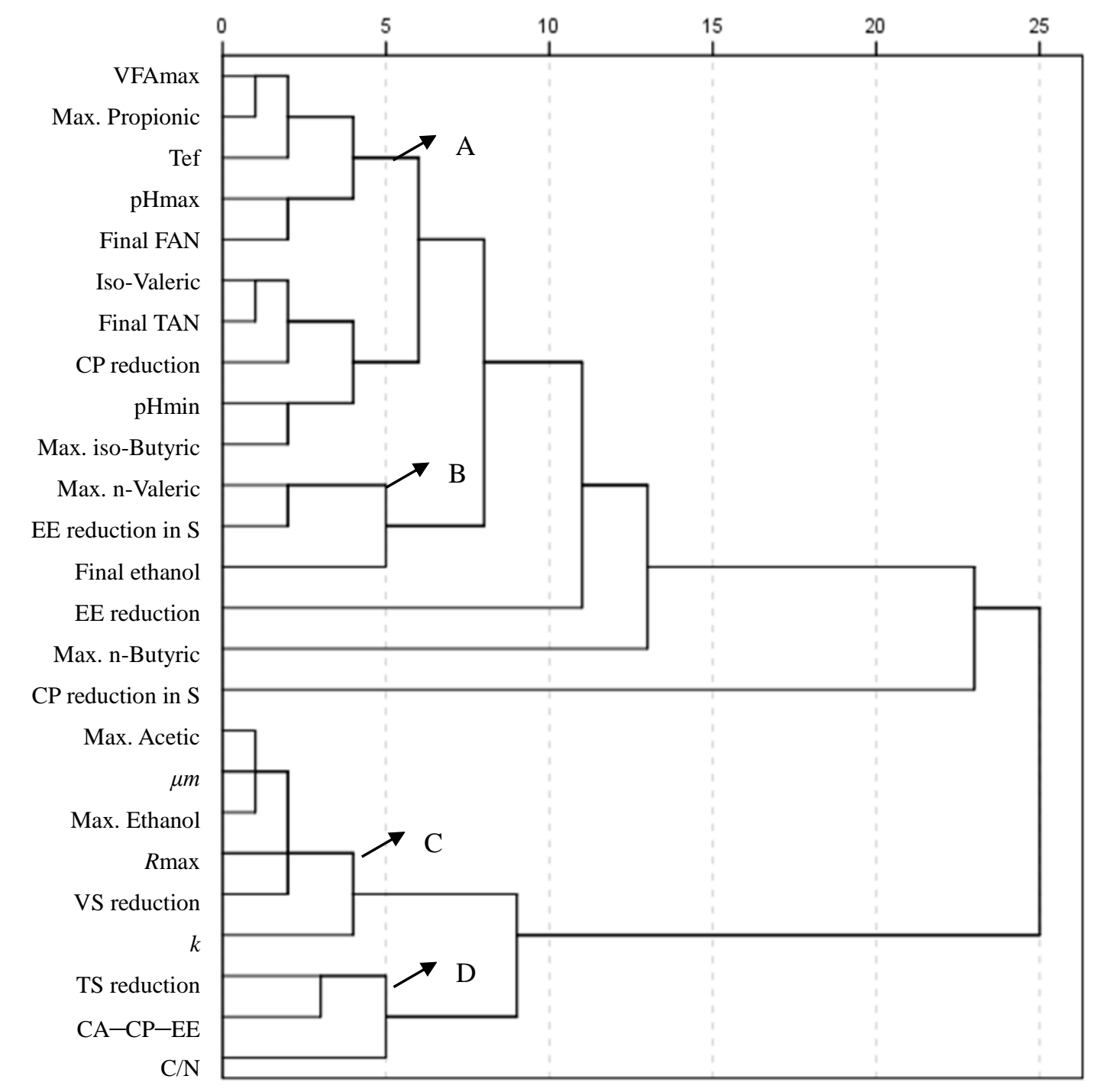

43

44 Fig. 6. A dendrogram of the cluster analysis measured by Euclidean distance (The axis

45 at the top indicates relative similarity of different cluster groups. The samller the

46 distance, the greater the similarity between objects). 